Manuscript accepted: 10 September 1998 Nurse Education Today (1999) 19, 313318313

http://www.sciencedirect.com/science/article/pii/S0260691799906421

\title{
A taxonomy for developing Cultural Competence
}

\section{Philip Lister}

This paper proposes a taxonomy to develop Culturally competent practitioners. Arguments about what this might mean and how this could be achieved are discussed first, identifying problems with multicultural and antiracist approaches. The model follows the cognitive, emotional and behavioural levels of Steinaker and Bell's experiential taxonomy. Five elements are proposed: Cultural awareness, Cultural knowledge, Cultural understanding, Cultural sensitivity and cultural competence. These could address, in increasingly Sophisticated and increasingly praxis-oriented ways, issues of power and the construction of meanings and identities which go beyond essentialist notions of ethnicity.

\section{Introduction}

The professional education of nurses needs to produce practitioners who are competent in taking account of the customs, values and beliefs of clients. This paper outlines some of the conflicting positions in the debate about how best to deal with issues of ethnicity and culture, mainly in the UK context. It proposes a taxonomy to guide curriculum development, which reflects the contested nature of the issues. Links are made with other curriculum models: specifically the experiential taxonomy'. It is proposed that this taxonomy will prove useful even when the implicit multicultural agenda moves on, following critiques discussed below.

\section{Background}

Since the 1980s, courses leading to a nursing registration in the UK have been required to address multicultural issues in their curricula. This followed the national regulatory body's publication of a code of professional conduct which charged nurses with taking account of the customs, values and beliefs of clients (UKCC 1984). This was in the context of a growing weight of evidence suggesting ethnic inequalities both in health (Donovan 1984, Ahmad 1993, Smaje 1995) and in the composition of nursing as a workforce (Pearson 1989).

This led to the Royal College of Nursing (RCN) publishing an audit tool for course administrators, reinforcing the multi-cultural dimensions of the Code of Professional 
Conduct (UKCC 1992, RCN 1993).

There is considerable debate, however, over how best to achieve positive changes both in hospital services and in community care (Ahmad 1996). This debate is international, and has a longer history in countries such as the USA (Deloughey 1995). It will be seen that the definition and role of 'culture' is central in this contested debate. The two main positions in the debate outlined below are represented by multiculturalism, as reflected in the concept of transcultural nursing, and by antiracism. More recent critiques of these positions are represented by the social realist approach.

\section{Multiculturalism and critiques of multiculturalism}

Those working for a 'transcultural nursing approach' (Leininger 1976, 1978, 1991) argue that there should be recognized nurses who have specialist training, experience and expertise in relation to specific ethnic groups. In this view, the definition of culture as a shared way of life, of customs and lifestyle, is the key to understanding the problem and finding solutions. Professionals and clients need access to adequate information and to the services of interpreters. The implicit multiculturalist assumptions in this view have been challenged.

Critics argue that framing problems to do with ethnic health inequalities and inequalities of opportunity in purely cultural terms is misleading (Culley 1996). They argue that the transcultural approach sees inequalities as merely the result of the failure of the majority group to demonstrate familiarity with the cultural practices of minority groups.

This, it is argued, plays down the economic and social effects of racist practices at the individual and institutional level. Some writers have suggested that biological ideas of racial differences have been replaced with ideas of race as being 'cultural' (Brehm \& Kassin 1990, Fernando 1995). That is, culture and tradition are assumed to be inherent and fixed. From this position, it could be argued that transcultural nursing reinforces this New Racism' (Barker 1981).

Another argument in the debate might be that ethnicity and culture are not issues if individualized holistic care is the philosophy. To be effective, this approach must obviously take into account the cultural background of the individual and his or her life experiences, including discrimination and prejudice. There is some evidence, however, that an espoused commitment to individualized holistic care does not always lead to such issues being addressed (Papadopolous et al. 1995). This could be the result of an unwitting ethnocentricity on the nurse's part, or of the institution. That is, the institutional practices and individual nurses' attitudes may expect members of minority groups to assimilate into existing health-care patterns that themselves mainly reflect the needs of the majority ethnic population (Mulholland 1995) 
Fernando (1995) argues that approaches which stress 'culture' will be prone to stereotyping individuals. An individual from a recognized ethnic group (recognised on the basis of appearance or of stated place of birth) may have a complex relationship with the culture of that group. He or she may participate fully in the traditions and practices of the group, or may identify more with the majority culture. Or there may be ambivalence or a fluidity of identification among different cultural formations depending on particular circumstance.

Instead of a multicultural or antiracist model, Fernando proposes a relativist multisystemic ( $p$ 202) approach in relation to assessing problems in a multi-disciplinary way. He describes this as a 'social realist' approach in that it makes central the individual's relationships, values, beliefs and practices in the context of social structures such as the medical, educational and even judicial systems.

Though this model was developed for mental health assessment, it could be applied to other nursing and caring situations. It depends on professionals and client/users working together in the context of a 'clear understanding of contemporary racism and a meaningful understanding of "culture" (Fernando 1995 p214).

Given the desire to correct imbalances and inequalities between different groups in society, then, the appropriate course of action is far from clear. Transculturalists see the solution in education and information; antiracists see the challenging of personal and institutional racist attitudes and practices to be the way forward; the Social realist approach emphasizes partnership and a sophisticated awareness of 'racism' and 'culture'.

In the light of the debate outlined above, we need to respond to the political will to address ethnic inequalities in health. In the UK this will has been expressed in, for example, the Government White Paper which preceded the Community Care Act (Cmnd 1989) where it was exhorted that community care be sensitive to the needs of ethnic minorities and planned in consultation with them. Despite a change in Government the intentions to provide services which meet the needs of ethnic minority groups are still clearly held (Department of Health 1997, 1998a) as are intentions to increase the representatives of such groups in higher service positions (Department of Health 1998b, 1998c).

This will was also carried through in the work of the statutory board for nursing's commissioned research on the efficacy of training/education programmes to meet the needs of these minority groups (Gerrish 1997, Gerrish et al., 1997). 
Given this will, shared across political parties, the curriculum needs to provide a way of developing nursing students' competencies in relation to working with and across a variety of ethnic groups.

\section{A taxonomy of cultural competence}

One way of structuring the development of these themes within the curriculum could be the model suggested below. It is the author's extension of a schema outlined by Papadopolous et al. (1995). Central to this new model is a definition of culture as a process, a set of practices to do with the construction of meaning and identity (Woodward 1997). This gives the notion of 'culture' a fluidity which marks its difference to essentialist and racist definitions criticized above, i.e. those which assume culture to be a fixed set of traditional practices.

Rattansi (1992) argues that it is no longer sufficient to conceive of 'culture' in terms of religious beliefs, communal rituals and shared traditions of a community. Rather, they argue, the emerging traditions of post-modernism and poststructuralism should be used to critically rethink the relationships between culture, common-sense concepts of "race', and structures of power in society.

The taxonomy of cultural competence suggested here reflects these concerns. The levels address, in increasingly sophisticated and increasingly praxis-oriented ways, issues of power and the construction of meanings and identities. The five levels which could be addressed progressively through the curriculum are outlined below.

The concerns and perspectives embodied in this framework reflect similar concerns within the concept of 'cultural safety", as developed in New Zealand (Polaschek 1998). Whereas the cultural safety model refers to competent practice which protects and enhances the rights of the indigenous minority, issues of identity, disempowerment, professional/personal self-awareness, and political action are central to both models. This taxonomy provides a structure for planning the development of safe cultural practice.

\section{Links with the experiential taxonomy}

The structure follows a similar cognitive, affective and behavioural sequence as Steinaker and Bell's taxonomy of experiential learning, which should be familiar to many curriculum planners

(Steinaker \& Bell 1979). This cultural competence (CC) framework maps onto the experiential taxonomy (ET) as described below. 
Cultural awareness: the student is able to describe how beliefs, values and personal/political power are shaped by culture, and that different cultures, subcultures and ethnicities may validate different beliefs and values.

Cultural knowledge: the student begins to show familiarity with the broad differences, similarities, and inequalities in experience, beliefs, values, and practices among various groupings within society.

Cultural understanding: the student recognizes the problems and issues faced by individuals and groups when their values, beliefs and practices are compromised by a dominant culture.

Cultural sensitivity: the student shows regard of an individual client's beliefs, values and practices within a cultural context, and shows awareness of how their own cultural background may be influencing professional practice.

Cultural competence: the student provides or facilitates care which respects the values, beliefs and practices of the client, and which addresses disadvantages arising from the client's position in relation to networks of power.

\section{Awareness (CC)/exposure (ET): recognition of variety and possible variables;} accurate perception of differences

For example, an early session taught with student nurses and midwives in this college involves them sharing something of their backgrounds in small groups. From this, they are asked to identify the variety of ways in which individuals can differ from one another, and how groups can share common characteristics. Definitions of ethnicity and culture are then discussed and applied to the material that the students have generated.

\section{Knowledge/participation: discovering Sources of information; collecting data}

An early assignment in the same course module involves students researching a neighbourhood profile, which includes them finding sources of information about that locality including its ethnic composition. They are asked to evaluate the degree to which local health-care services meet the needs of minority groups. This is supported by sessions on inequalities in health (in relation to social class), gender, ethnicity and age.

\section{Understandings/identification: developing an ability to understand a different lifeworld through testing hypotheses}

An example of this level, using the much broader conceptualization of 'culture suggested by Woodward (1997) and discussed above would be the following: one assignment in a later module of the same course requires the student, using a case study from practice, to compare and contrast lay and professional views and 
experiences of illness/ disorder and the caring relationship. Students choosing a case study from their mental health practice sometimes identify clients who regard themselves as part of the 'users' or 'survivors' culture. These studies often demonstrate cultural understanding, as defined here.

\section{Sensitivity/internalization: practice development; new skills and attitudes change behaviour}

In a post-registration degree module (Healthcare needs of people from ethnic minorities) for practicing nurses and midwives, these professionals are asked to consider issues related to this level of the taxonomy. A significant assignment in this module requires the student to evaluate the effectiveness of their own area of service provision in meeting these needs. This is supported by sessions which facilitate reflection and analysis at the level of the student's own practice and at the institutional, professional and political levels. Evaluation of the module indicates changes in attitude and practice.

\section{Competence/dissemination: publicly acting to engage others; acceptance of responsibility to promote others' professional development; political involvement at various levels}

Processes such as clinical supervision, mentorship (Butterworth \& Faugier 1992), and professional profiling (Teesdale 1995) would facilitate development at this level of the taxonomy.

As the cultural competence model maps onto the experiential taxonomy it could be readily integrated where the curriculum is planned on the basis of this. But it could also be used to structure the way multi-cultural issues are addressed throughout a course or a module, and how professional competence can be enhanced, whatever the curriculum design. For example, the diploma course from which some of the above examples are drawn uses elements of Blooms taxonomy and Lawton's curriculum model in the validated course documentation. It has nevertheless been possible within that to begin to introduce a sequence of sessions throughout the course which are informed by the structure of this cultural competence model.

Earlier sessions in a course which has integrated this cultural competence model aim to facilitate the first stages of the taxonomy, i.e. developing awareness of how the student's own experience has been shaped by particular cultural factors, and knows how to gain access to resources to enhance knowledge of different cultural experiences. These have a relatively high degree of tutor facilitation and direction. Later sessions would encourage the student to provide evidence of empathic and skilled practice as in the examples discussed above. The 'Awareness' level example requires a higher degree of tutor facilitation, whereas the 'Competence' example requires selfawareness, self-motivation and professional engagement. 
This taxonomy can provide a framework for identifying reasonable expectations of different levels of courses. Pre-registration training may not provide the opportunity to develop the higher level skills identified by the taxonomy. This is because at this level the student would probably need to be engaged in practice with a relatively high degree of responsibility and authority. But even at the pre-registration level the taxonomy can provide the cognitive framework for developing higher levels. Post-registration courses can provide the stimulus and opportunities in practice to develop these higher levels.

\section{Ethnicity and culture}

One criticism of the cultural competence taxonomy as presented above could be that it makes no specific reference to ethnicity when the political agenda seems to be conflating 'culture' with 'ethnicity as identified earlier (Donovan 1984, RCN 1993, Cmnd 1989), where the phrases 'multi-cultural' and 'multi-ethnic both stand in for minority groups of relatively recent immigrant background.

As it stands, though, the model could possibly be used to structure a curriculum that explored the differences among various social groupings defined according to gender, generation, lifestyle, or class as much as ethnicity.

Support for this broader approach is given by critiques of multiculturalism and antiracism (which both privilege ethnicity) which specifically note the absence of reference to other Social categories, such as socioeconomic class and gender (Rattansi 1992, Lillie-Blanton \& Laveist 1996). That is, inequalities are usually seen primarily as a function of ethnicity, whereas class or gender analyses within and among ethnic groups can show more complex relationships.

It is proposed that this model may, therefore, be useful in addressing the complex networks of inequalities between various social groupings, several of which any individual could belong to at any one time, each positioning the subject within the structures of power operating at that moment and place (Bradley 1992). People negotiate their own identities within the constraints of others' expectations. For example, an individual who is from an ethnic minority group may act and feel differently when with close friends compared to when meeting healthcare workers. The circumstances and role expectations are very different. Ethnicity as such may or may not be an issue in either situation. What certainly will be an issue is how meanings are shared and negotiated within the context of power relations, e.g. the notion of 'culture' as used by Rattansi (1992) and Woodward (1997).

\section{Conclusion}

This paper has outlined a taxonomy for developing cultural competence. It is hoped that the ideas presented here will contribute to the debate about how to improve the way multicultural and multi-ethnic issues are addressed in nursing curricula, not least by raising the possibility of a critical engagement with these terms. 
The taxonomy for cultural competence suggests a way of planning learning and teaching activities which will sensitize students to the need for recognizing the cultural context of caring, and will provide them with a cognitive structure for developing modes of care delivery that are empowering to disadvantaged individuals and groups in Society.

\section{References}

Ahmad W (ed) 1993 'Race' and health in contemporary Britain. Open University Press, Buckingham

Ahmad W, Atkin K (eds) 1996 'Race' and community care. Open University Press, Buckingham

Barker M1981 The New Racism, Junction Books, London

Bradley H 1992 Changing social divisions: class, gender and race. In: Bocock R, Thompson K(eds). Social and cultural forms of modernity. Polity Press, Cambridge, $p$ 12-67

Brehm S, Kassin S 1990 Social psychology. Houghton Mifflin, Boston

Butterworth T, Faugier J 1992 Clinical Supervision and Mentorship in Nursing.Chapman \& Hall, London

Cmnd 8461989 Caring for people, HMSO, London

Culley L. 1996 A critique of multiculturalism in health care: the challenge for nurse education. Journal of Advanced Nursing 23:564-570

Deloughey G 1995 Issues \& trends in nursing 2nd ed. Mosby, St Louis

Department of Health 1997 The New NHS: Modern, Dependable. The Stationary Office, London

Department of Health 1998a 1.3 million funding to improve ethnic minority health. DoH press release 98/052, February 5

Department of Health 1998b Frank Dobson launches NHS equal opportunities award. DoHpress release 98/118, March 30

Department of Health 1998c Public appointments report shows more women and ethnic minorities in top NHS jobs. DoH press release 98/240, June 17

Donovan J 1984 Ethnicity and health: a research review. Social Science and Medicine 19(7): 663-670

Fernando S 1995 Mental health in a multi-ethnic society: a multi-disciplinary handbook. Routledge, London

Gerrish K 1997 Preparation of nurses to meet the needs of an ethnically diverse society: educational implications. Nurse Education Today 17(5):359-65 
Gerrish K, Husband C, MacKenzie J 1997 Nursing for a multi-ethnic society. Open University Press, Milton Keynes

Leininger M.1976 Transcultural Health Care, issues and conditions. F A Davies, Philadelphia

Leininger M 1978 Transcultural Nursing Concepts, theories and practices. Wiley, New York

Leininger M 1991 Cultural Care Diversity and Universality: a theory of nursing. NLN Press, New York

Lillie-Blanton M, Laveist T 1996 Race/ethnicity: the social environment and health. Social Science and Medicine 43(1): 83-91

Mulholland J 1995 Nursing, humanism and transcultural theory: the bracketing-out of reality. Journal of Advanced Nursing 22:442-449

Papadopolous I, Alleyne J, Tilki M 1995 Teaching transcultural care. Middlesex University, London

Pearson M 1989 Sociology of race and health. In: CruikshankJ, Beevers D (eds). Ethnic factors in health and disease. Wright, London

Polaschek N 1998 Cultural safety: a new concept in nursing people of different ethnicities. Journal of Advanced Nursing 27:452-457

Rattansi A 1992 Changing the subject? Racism, culture and education. In: Donald J, Rattansi A (eds). Race, culture \& difference. Sage, London, p11-48

Royal College of Nursing 1993 Curriculum audit tool for course administrators. RCN, London

Smaje C 1995 Health, 'race' and ethnicity. King's Fund Institute, London

Steinaker N, Bell M. 1979 The experiential taxonomy: a new approach to teaching and learning. Academic Press, New York

Teasdale K 1995 Developing a personal professional profile. Nusing Standard 10(2): 803-5

United Kingdom Central Council for Nurses, Midwives and Health Visitors 1984 Code of professional conduct, 1st ed. UKCC, London

United Kingdom Central Council for Nurses, Midwives and Health Visitors 1992 Code of professional conduct, 3rd ed. UKCC, London

Woodward K (ed) 1997 Identity and difference. Sage, London 
